\title{
Superstition in the Housing Market ${ }^{1}$
}

\author{
By Nicole M. Fortin, Andrew Hill and Jeff Huang
}

October 2010

\footnotetext{
${ }^{1}$ Department of Economics, University of British Columbia, Vancouver, BC, V6T 1Z1. We thank Tsur Somerville for kindly giving us access to the housing data. David Card, Philip Oreopoulos, Tom Davidoff, and seminar participants at the University of British Columbia provided valuable comments on the paper. Nicole Fortin acknowledges the support of the Canadian Institute for Advanced Research and of the Social Sciences and Research Council of Canada.
} 
When the Beijing Summer Olympics opened at 08:08:08 pm on the $8^{\text {th }}$ day of the $8^{\text {th }}$ month of 2008, it was shown to the world that the Chinese take the auspiciousness of the number " 8 " seriously. In Las Vegas, where superstitious beliefs are rampant, many large casino-hotels (such as MGM, Wynn and Palms Place) omit floor numbers 4, 14, 24, 34 and 40 to 49 because the number " 4 " is considered unlucky in the Chinese tradition. ${ }^{2}$ This tetraphobia comes from the fact that the pronunciation of the word for four (四： si) is very similar to the word for death (死: sî) in Mandarin, Cantonese, and several Chinese dialects. On the other hand, the word for eight (八: $b \bar{a})$ is phonetically similar to the word for prosperity or wealth (发: fā). In this paper, we attempt to price the value of auspicious and inauspicious Chinese numbers in street addresses in the Greater Vancouver residential market.

Although Vancouver, B.C., has a long history of Chinese immigration dating back to the construction of the Canadian Pacific Railway in the $19^{\text {th }}$ century, the impending return of Hong Kong to the People's Republic of China in 1997 sent a new wave of immigrants from Hong Kong in the 1980s and 1990s. ${ }^{3}$ Since then, Vancouver has continued to see a large number of immigrants from mainland China, many of them relatively well-off and admitted as business or skilled worker applicants. These large influxes of immigrants resulted in the development of several Chinese ethnic enclaves in Greater Vancouver. ${ }^{4}$ This allows us to exploit differences in

\footnotetext{
${ }^{2}$ Some hotels also omit the $13^{\text {th }}$ floor considered unlucky in the Western tradition. In Vancouver, many new residential towers also skip the floors numbers that include a four.

${ }^{3}$ Chinese immigration flows were curtailed with the imposition of a head tax in 1885, and banned formally in 1923. While there was a continuous trickle of Chinese refugees thereafter, the relaxation of ethnic restrictions in Canadian immigration regulations in the 1970s saw a dramatic increase in the number of immigrants from China.

${ }^{4}$ See Feng Hou and Garnett Picot (2004) for details.
} 
the concentration of ethnic Chinese residents across census tracts to identify the effect of the lucky and unlucky numbers and claim that they are driven by Chinese superstitious beliefs. ${ }^{5}$

We combine a large and detailed real estate data set containing information on all singlefamily house sales (close to 117,000 transactions) in the Greater Vancouver area over the fiveyear period from January 2000 to May 2005 with census tract (CT) information from the 2001 Canadian Census. Our empirical specification begins with a classic hedonic analysis (Sherwin Rosen, 1974) of the log transaction price where the structural, locational and neighborhood attributes of a house are thought to affect price. In addition to a host of structural house attributes, we control for detailed location characteristics by including street and CT fixed effects, and we control for seasonal and yearly price effects with month-year fixed effects.

We focus our search for the effects of superstitious beliefs on house street numbers ending with the digits four and eight as these beliefs are thought to be greatest and the last digit of a house number is thought to leave a final impression in the pronunciation of one's address. ${ }^{6}$ There may be other digits or combinations of digits in the house number also associated with superstitious beliefs for which we perform some limited tests.

We employ a difference-in-difference estimation strategy. Once we control for CT fixed effects and the Chinese concentration in the $\mathrm{CT}$, the coefficient of the interaction between the fateful house street numbers and the Chinese concentration in the CT gives us the relative price effect of fateful house numbers in Chinese neighborhoods in comparison to other neighborhoods.

\footnotetext{
${ }^{5}$ While ethnic Chinese made up about 18 percent of the total population of Greater Vancouver in 2001 , there are 22 census tracts in Vancouver and its suburb of Richmond where the percentage of ethnic Chinese residents exceeded 50 percent of the population. We note that in Chinese, Richmond translates as the "City of Rich Gate" since "mond" has the same pronunciation as "gate" in Chinese.

${ }^{6}$ In alternative specifications, we have found the last digit effects dominate the effects of different positions of the fateful digits. In a related literature investigating the role of superstitious beliefs in marketing, Lee Simmons and Robert Schindler (2002) similarly focus attention on the last digit of the price.
} 
We find that in neighborhoods where the percentage of Chinese residents exceeds the Greater Vancouver average of 18 percent, houses with street numbers ending in " 4 " are sold at a 2.2 percent discount and those ending in " 8 " are sold with a 2.5 percent premium in comparison to houses with street numbers ending in any other digits. We argue below that the magnitude of these effects is consistent with transaction costs limiting arbitrage opportunities. Our results add weight to the argument that transaction costs and heterogeneous preferences limit the efficiency of the market for single-family homes (Karl Case and Robert Shiller, 1989).

We are aware of two other papers that study the effects of lucky and unlucky Chinese numbers in residential markets. Steven Bourassa and Vincent Peng (1999) consider the effect of unlucky and lucky house numbers on 2,164 house sales in a few neighborhoods of Auckland, New Zealand. ${ }^{7}$ Kwong Wing Chau, Vincent Ma and Daniel Ho (2001) investigate the effects of lucky floor numbers 8, 18 and 28 on 1,019 apartment sale prices in Hong Kong. ${ }^{8}$ Although both studies present some evidence of a potential effect of Chinese superstitious beliefs on house prices, they are limited by small sample sizes and by the lack of clear control groups. We thus claim to provide the first solid evidence that superstitious beliefs have statistically and quantitatively significant effects on transaction prices in thick North American residential markets. Other papers (Chi-Keung Woo, Ira Horowitz, Stephen Luk, and Aaron Lai, 2008; Travis Ng, Terence Chonga and Xin Du, 2009) investigate the impact of superstitious beliefs on the value of Hong Kong license plates. This is arguably a thin market where the absence of a resale market prevents prices to be observed on the equilibrium path.

\footnotetext{
${ }^{7}$ Bourassa and Peng (1999) further argue that the Chinese homophonic principles of number interpretation are linked to the practice of feng sui, a system which is intrinsically linked to the Taoist philosophy and is more substantial than simple superstitions.

${ }^{8}$ Chau et al. (2001) use the transaction records of apartment sales from only one private sector real estate company in Hong Kong's apartment market, which is not necessarily representative of the entire market.
} 


\section{Data and Empirical Methodology}

We use high quality housing data compiled by the property assessment firm, Landcor Data Corporation. This firm works closely with the British Columbia Assessment Authority (BCAA), a public corporation responsible for property assessments used to establish property taxes. From the complete universe of transaction records over the five-year time period, we select sales transactions for single-family dwellings for 13 major cities in the Greater Vancouver area. ${ }^{9}$ The housing information includes the street address, the date of the transaction and the transaction price, as well as a host of structural house characteristics: lot size, finished floor area, finished basement area and total basement area, house age, number of bedrooms, full bathrooms, half bathrooms, single-car garages, multi-car garages and stories, and the presence of a basement suite and a swimming pool. ${ }^{10}$

The sales transactions data are merged with data for $363 \mathrm{CTs}$ using postal codes. ${ }^{11}$ The census provides information on the average characteristics of the CT based on interviews of one in five residents in the $\mathrm{CT} .{ }^{12}$ The census asks many questions about immigrant status, country of origin, languages spoken, single and multiple ethnicities, and visible minority status. We use the Chinese category of the visible minority status question to compute the proportion of ethnic Chinese residents in a $\mathrm{CT}$ to avoid the problem of double counting people with multiple ethnicities.

\footnotetext{
${ }^{9}$ These include Burnaby, Coquitlam, Delta, Langley, Maple Ridge, New Westminster, North Vancouver, Pitt Meadows, Port Coquitlam, Richmond, Surrey, Vancouver, and West Vancouver.

${ }^{10}$ We exclude observations below $\$ 100,000$ as these are likely to include "other considerations" as part of the transaction, as well as properties with lot sizes exceeding 10,000 square feet. Descriptive statistics on the housing and CT data are available in the online Appendix.

${ }^{11}$ Each street address in the sales transactions data is matched to a postal code, and this postal code is matched to a CT through the postal code conversion files provided by the Canadian Census Analyzer at the University of Toronto.

${ }^{12}$ Census tract populations range from 280 to 11,915 residents in our area of interest.
} 
Our more complete empirical specification subsumes the classic hedonic price regression on the logarithm of transaction price, of observation $i$ on street $s$ in CT $c$ at time $t$,

$$
\begin{aligned}
\ln \left(P_{i s c t}\right)= & \beta_{0}+\beta_{4} L 4_{i s c t}+\beta_{8} L 8_{i s c t}+\boldsymbol{H}_{i s c t}^{\prime} \boldsymbol{\alpha}_{H}+\boldsymbol{D}_{t}^{\prime} \boldsymbol{\alpha}_{t}+\boldsymbol{D}_{s}^{\prime} \boldsymbol{\alpha}_{s}+\boldsymbol{D}_{c}^{\prime} \boldsymbol{\alpha}_{c} \\
& +\delta_{e} E_{c}+\delta_{4 e} E_{c} * L 4_{i s c t}+\delta_{8 e} E_{c} * L 8_{i s c t}+\varepsilon_{i s c t}
\end{aligned}
$$

where $L 4_{\text {isct }}$ and $L 8_{\text {isct }}$ denote a house street number ending with a four or an eight, respectively, $\boldsymbol{H}_{i s c t}^{\prime}$ is a vector of house characteristics, and $\boldsymbol{D}_{t}^{\prime}, \boldsymbol{D}_{s}^{\prime}$ and $\boldsymbol{D}_{c}^{\prime}$ are vectors of month-year, street, and CT dummies to control for time and location effects. The Chineseness of the census tract is identified with the variable $E_{c}$. The parameters $\beta_{4}$ and $\beta_{8}$ thus capture the base effect (in the non-Chinese neighborhoods) on log transaction price of a house street address ending with the fateful numbers, and the parameters $\delta_{4}$ and $\delta_{8}$ capture the added effect of the fateful numbers in Chinese neighborhoods.

\section{Empirical Results}

We begin in Table 1 by establishing the distinctiveness of the numbers " 4 " and " 8 " by regressing the last digit of the house address on log transaction price, controlling for house characteristics and including 52 month-year dummies. Columns (1) and (2), respectively omitting the numbers " 4 " and " 8 ", show that the effect of the other digits are all statistically different from the omitted category $(\mathrm{F}$-statistic $=29.83)$, positive in the first case and negative in the second case. We note that none of the other digits have this property. ${ }^{13}$

Column (3) shows that without location controls, the negative price effect of a house number ending in four $\widehat{\beta}_{4}$ is about 3.1 percent, and the positive price effect of a house number

\footnotetext{
${ }^{13}$ For each other last digit, the effect of at least one other last digit is not statistically distinguishable. For example, the effects of "0" and "5", "2" and "7" and all of "1", "3", "6" and "9" are not statistically different.
} 
Table 1. Distinctiveness of " 8 " and "4" in the Effect of House Street Number

On Log Transaction Price

\begin{tabular}{llll}
\hline & \multicolumn{1}{c}{$(1)$} & \multicolumn{1}{c}{$(2)$} & $(3)$ \\
\hline Last digit $=0$ & $0.045^{* * *}$ & $-0.020^{* * *}$ & \\
& $(0.005)$ & $(0.004)$ \\
& & \\
Last digit $=1$ & $0.027^{* * *}$ & $-0.037 * * *$ \\
& $(0.005)$ & $(0.004)$ \\
& & \\
Last digit $=2$ & $0.019^{* * *}$ & $-0.046^{* * *}$ \\
& $(0.005)$ & $(0.004)$ \\
Last digit $=3$ & $0.026^{* * *}$ & $-0.038^{* * *}$ \\
& $(0.005)$ & $(0.005)$ \\
Last digit $=4$ & & $-0.065^{* * *}-0.031^{* * *}$ \\
& & $(0.005)$ & $(0.004)$ \\
Last digit $=5$ & $0.043 * * *$ & $-0.022^{* * *}$ \\
& $(0.005)$ & $(0.004)$ \\
Last digit $=6$ & $0.024 * * *$ & $-0.040^{* * *}$ \\
& $(0.005)$ & $(0.004)$ \\
Last digit $=7$ & $0.017 * * *$ & $-0.048^{* * *}$ \\
& $(0.005)$ & $(0.005)$ \\
Last digit $=8$ & $0.065^{* * *}$ & & \\
& $(0.005)$ & & $0.034 * * *$ \\
Last digit $=9$ & $0.030^{* * *}$ & $-0.035^{* * *}$ \\
& $(0.005)$ & $(0.004)$ \\
Adj. $\mathrm{R}^{2}$ & 0.444 & 0.444 & 0.443 \\
\hline & &
\end{tabular}

Note: The dependent variable is the natural logarithm of house transaction price. Standard errors are in parentheses. Asterisks indicate the level of statistical significance: $* * * \mathrm{p}<0.01, * * \mathrm{p}<0.05, * \mathrm{p}<0.10$. All regressions include year-month dummies and the following house characteristics: lot size, finished floor area, finished basement area and total basement area (all in $1000 \mathrm{sq} \mathrm{ft}$ ), house age (10 years), house age squared (100 years), number of full bathrooms, of half bathrooms, of single car garages, of multi-car garages, of stories, dummies for basement suite and and pool. There are 116,939 observations.
Table 2. Impact of Chinese Ethnicity on the Effect of a House Street Number Ending with a "4" or a "8" on Log Transaction Price

\begin{tabular}{|c|c|c|c|}
\hline & $(1)$ & $(2)$ & (3) \\
\hline Ethnicity & None & Above & Proportion \\
\hline Control & & $\begin{array}{c}\text { Average } \\
\text { in CT }\end{array}$ & in $\mathrm{CT}$ \\
\hline Chinese & & $\begin{array}{c}0.616 \\
(0.386)\end{array}$ & $\begin{array}{c}14.66 \\
(17.77)\end{array}$ \\
\hline Interaction with & & $-0.022 * * *$ & $-0.056 * * *$ \\
\hline Last digit $=4$ & & $(0.007)$ & $(0.020)$ \\
\hline Interaction with & & $0.025 * * *$ & $0.065 * * *$ \\
\hline Last digit $=8$ & & $(0.005)$ & $(0.013)$ \\
\hline Last digit $=4$ & $\begin{array}{l}-0.002 \\
(0.003)\end{array}$ & $\begin{array}{c}0.002 \\
(0.003)\end{array}$ & $\begin{array}{c}0.004 \\
(0.004)\end{array}$ \\
\hline Last digit $=8$ & $\begin{array}{l}0.008 * * * \\
(0.002)\end{array}$ & $\begin{array}{l}-0.001 \\
(0.003)\end{array}$ & $\begin{array}{l}-0.003 \\
(0.003)\end{array}$ \\
\hline $\begin{array}{l}\text { Census Tract } \\
\text { Dummies }\end{array}$ & Yes & Yes & Yes \\
\hline $\begin{array}{l}\text { Street Fixed } \\
\text { Effects }\end{array}$ & Yes & Yes & Yes \\
\hline Adj. R-squared & 0.756 & 0.756 & 0.758 \\
\hline
\end{tabular}

Note: The dependent variable is the natural logarithm of house transaction price. Standard errors are in parentheses. Asterisks indicate the level of statistical significance: $* * * \mathrm{p}<0.01,{ }^{* *} \mathrm{p}<0.05, * \mathrm{p}<0.10$. All regressions include year-dummies and the same house characteristics as Table 1.

ending in eight $\widehat{\beta}_{8}$ is about 3.4 percent in comparison to house numbers ending in any other digit. 
In Table 2, we add our extensive set of locational controls; street (6100 dummies) and CT fixed effects (363 dummies) respectively capture location attributes, such as views or commercial streets, and neighborhoods amenities, such as school quality, proximity to rapid transit, or ethnic mix. ${ }^{14}$ Column (1) shows that the effects of fateful numbers are entirely absorbed by our location controls. In Columns (2) and (3), we unbundle the effects of location controls by singling out the effect of Chinese ethnicity. In Column (2), Chinese ethnicity $E_{c}$ is measured using a dummy indicating an above average percentage (greater than 18 percent) of Chinese residents in the CT. The estimated values of $\hat{\delta}_{4}$ and $\hat{\delta}_{8}$ indicate a 2.1 percent discount and a 2.5 percent premium arising from the fateful numbers in CTs with above average Chinese ethnicity. ${ }^{15}$ In Column (3), $E_{c}$ is measured by the proportion of ethnic Chinese in the CT. It shows that as the proportion of Chinese residents increases by one percent, the discount for the "death"-ridden number "4" increases by 5.5 percent and the premium arising from the "prosperity"-laden number " 8 " increases by 6.4 percent. Importantly, the effects of the fateful numbers in non-Chinese neighborhoods, $\widehat{\beta}_{4}$ and $\widehat{\beta}_{8}$, go to zero, showing the effects of the fateful numbers originate from CTs with substantial proportions of residents potentially holding Chinese superstitious beliefs.

We conducted additional tests of other combinations of digits, notably the effects of house street numbers ending with the two-digit combination " 88 ", which resembles "double joy" or "happiness", and is sought after by real estate agents who cater to buyers from mainland China, and the two-digit combination "13", thought to be unlucky in the Western tradition. ${ }^{16}$

\footnotetext{
${ }^{14}$ For street fixed effects, we actually use the STATA command "areg" which absorbs the effects of 6,100 streets.

${ }^{15} \mathrm{We}$ begin to find significance for this interaction when the proportion of Ethnic Chinese residents reaches 15 percent.

${ }^{16}$ See the on-line Appendix for these results, as well as the mean of the variables used in the estimations. Note that there are 1670 houses ending with "88" and 658 houses ending with "13".
} 
First, adding these additional fateful combinations to specifications corresponding to Column (3) of Table 1 showed a statistically significant positive effect of 6.1 percent for the numbers ending in " 88 ", and a negative effect of 2.8 percent for the numbers ending in " 13 ". Second, these additions did not change the effects of the last " 4 " or the last " 8 " in both the specifications corresponding to Column (3) of Table 1 and Column (2) of Table 2. Third, we were unable to trace these added effects to the Chinese ethnicity, meaning that the corresponding parameters $\hat{\delta}_{88}$ and $\hat{\delta}_{13}$ were not statistically significant from zero. In the first case, we speculate that for Chinese buyers the desirability of the number " 88 " may exceed the desirability of living in a neighborhood with an above average proportion of ethnic Chinese residents. In the second case, the fact that the unluckiness of the numbers ending in " 13 " did not get any traction in Chinese neighborhoods is consistent with the view that it is not considered unlucky in the Chinese tradition.

\section{Interpretation}

In a market where opportunistic real estate agents interact with both superstitious and non-superstitious buyers, these results raise the basic question: why have arbitrage opportunities not driven the discount/premium to zero? First, there is anecdotal evidence that arbitrage opportunities are being exercised in other ways. Some homebuyers purchase houses with street numbers ending in " 4 " and then petition the cities for a change in house number. This should reduce the number of inauspicious houses for sale, and we do note that transactions with street addresses ending in "4" represent only 6.2 percent of all sales. ${ }^{17}$ Second, transaction costs, which importantly include the real estate agents' margins of between five and six percent equally split

\footnotetext{
${ }^{17}$ While this is much lower than the 10 percent predicted by a uniform distribution over the 10 digits, we do not know whether this is because there are fewer houses with street number ending in four or whether fewer such houses are put up for sale.
} 
between the home sellers and home buyers' agents, limit profitable arbitrage opportunities to the two to three percent range that we identify. Even when real estate agents themselves are involved in the transaction, they still have to pay the other agent's fee. ${ }^{18}$ We argue that further arbitrage opportunities are curtailed by transaction costs, and conclude that it is likely we have identified equilibrium outcomes.

Although we have traced the price effects of the numbers thought to be fateful in the Chinese tradition to a substantial presence of ethnic Chinese residents in the CT, we are unable to distinguish true superstitious beliefs from Veblen effects or from other psychological effects. Some buyers of auspicious house numbers may believe in the "magic" of the numbers, but others may simply enjoy the associated Veblen or status effects, gaining bragging rights or favourable treatment from family, friends, and clients. For others, the fateful numbers may act as a placebo pill and yield tangible benefits or costs. ${ }^{19}$

\section{Conclusion}

In this paper, we have shown that in the presence of sizeable transaction costs, superstitious beliefs associated with fateful Chinese numbers can sustain statistically and quantitatively significant effects on house prices, even in North American residential markets. With a mean nominal house price of about CAD $\$ 400,000$ over the sample period, we have found that in neighborhoods where the percentage of ethnic Chinese residents is at least 18 percent, houses with street numbers ending with the "death"-ridden "4" are sold at a \$8,000 discount and those

\footnotetext{
${ }^{18}$ Some also have to pay a portion to their firms, but some agents are independent. See Steven Levitt and Chad Syverson (2009) for other evidence that real estate agents are more informed than their clients.

${ }^{19}$ For example, David Phillips, George Liu, Kennon Kwok, Jason Jarvinen, Wei Zhang, and Ian Abramson ( 2001) find that for Chinese Americans and Japanese Americans, the peak of mortality among chronic cardiac patients occurs on the 4th of the month, a striking pattern not found among White Americans.
} 
ending with the "wealth"-laden " 8 " are sold with a $\$ 10,000$ premium in comparison to houses with street numbers ending in any other digit. These results highlight the role of high transaction costs in limiting the efficiency of the real estate market. Our paper also contributes to a developing economic literature that formally investigates the effects of superstitious beliefs.

\section{REFERENCES}

Bourassa, Steven C. and Vincent S. Peng, 1999. "Hedonic Prices and House Numbers: The Influence of Feng Shui," International Real Estate Review, 2(1): 79-93.

Case, Karl E. and Robert Shiller, 1989. "The Efficiency of the Market for Single-Family Homes," American Economic Review, 79(1):125-137.

Chau, K. W., Ma, Vincent and Daniel Ho, 2001. "The Pricing of 'Luckiness' in the Apartment Market," Journal of Real Estate Literature, 9(1): 31-40.

Hou, Feng and Garnett Picot. 2004. "Visible Minority Neighbourhoods in Toronto, Montreal and Vancouver," Canadian Social Trends, 72: 8-13.

Levitt, Steven D. and Chad Syverson, 2008. "Market Distortions When Agents Are Better Informed: The Value of Information in Real Estate Transactions,"The Review of Economics and Statistics, 90(4): 599-611.

Ng, Travis, Terence Chonga and Xin Du, 2009. "The Value of Superstitions," Journal of Economic Psychology, 31(3): 293-309.

Phillips, David P., George C. Liu, Kennon Kwok, Jason R Jarvinen, Wei Zhang, and Ian S Abramson. 2001. "The Hound of the Baskervilles Effect: Natural Experiment on the Influence of Psychological Stress on Timing of Death." British Medical Journal, 323(22-29): 1443-1446.

Rosen, Sherwin, 1974. "Hedonic Prices and Implicit Markets: Product Differentiation in Pure Competition," Journal of Political Economy, 82(1): 34-55.

Simmons, Lee C. and Robert M. Schindler, 2002. "Cultural Superstitions and the Price Endings Used in Chinese Advertising," Journal of International Marketing, 11(2): 101-111.

Woo, Chi-Keung, Ira Horowitz, Stephen Luk, and Aaron Lai. 2008. "Willingness to Pay and Nuanced Cultural Cues: Evidence from Hong Kong's License-plate Auction Market." Journal of Economic Psychology, 29(1): 35-53. 
Appendix - NOT INTENDED TO BE PART OF THE PUBLICATION

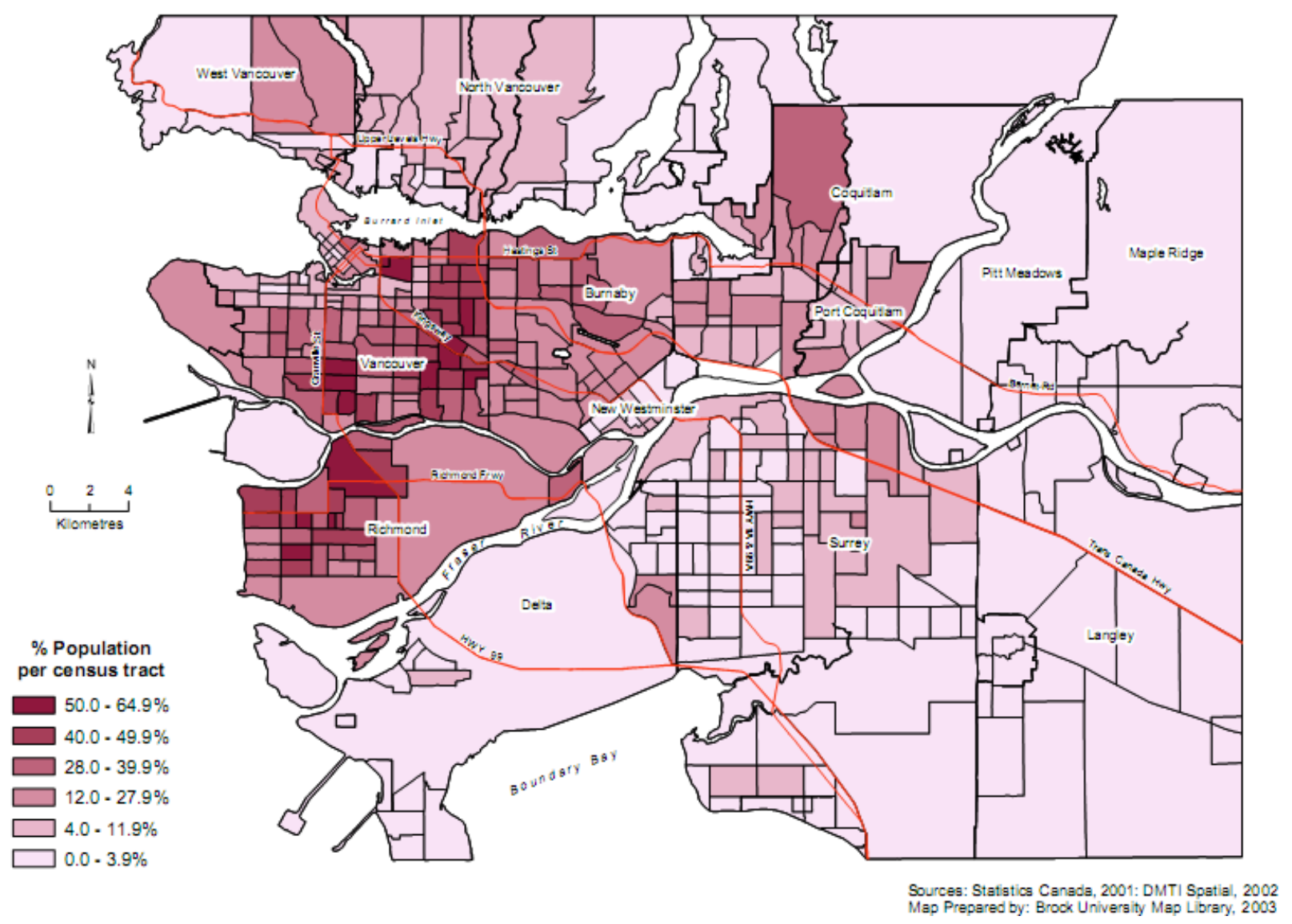

Figure A1. Percentage of Ethnic Chinese (Single Ethnic Origin) by Census Tract (2001) 
Appendix Table A1. Descriptive Statistics

\begin{tabular}{lrr}
\hline & \multicolumn{2}{c}{ Standard } \\
Housing variables & $376,999.40$ & 722.4957 \\
\hline Transaction price & 2407.71 & 2.9795 \\
Finished floor area (sq ft) & 809.50 & 6.2774 \\
Lot size (1000 sq ft) & 584.28 & 1.6150 \\
Finished basement area (sq ft) & 886.35 & 1.8505 \\
Basement area (sq ft) & 25.29 & 0.0656 \\
House age & 3.99 & 0.0037 \\
Number of bedrooms & 2.21 & 0.0034 \\
Number of full bathrooms & 0.60 & 0.0017 \\
Number of half bathrooms & 0.18 & 0.0011 \\
Number of single car garages & 0.57 & 0.0015 \\
Number of multi car garages & 1.43 & 0.0014 \\
Number of stories & 0.17 & 0.0011 \\
Basement suite (dummy) & 0.03 & 0.0005 \\
Swimming Pool (dummy) & &
\end{tabular}


Appendix Table A2. Impact of Chinese Ethnicity on the Effect of Other Digit Combinations in Street Number

on Log Transaction Price

\begin{tabular}{|c|c|c|c|c|}
\hline & (1) & (2) & (3) & (4) \\
\hline Ethnicity Control & None & $\begin{array}{c}\text { Above } \\
\text { average in } \\
\text { CT }\end{array}$ & None & $\begin{array}{c}\text { Above } \\
\text { average in } \\
\text { CT }\end{array}$ \\
\hline Chinese & & $\begin{array}{c}0.210 \\
(0.340)\end{array}$ & & $\begin{array}{c}0.210 \\
(0.340)\end{array}$ \\
\hline Interaction with & & $-0.022 * * *$ & & $-0.021 * * *$ \\
\hline Last digit $=4$ & & $(0.007)$ & & $(0.007)$ \\
\hline Interaction with & & $0.024 * * *$ & & $0.025 * * *$ \\
\hline Last digit $=8$ & & $(0.005)$ & & $(0.005)$ \\
\hline Interaction with & & 0.008 & & \\
\hline Last two digits $=88^{\mathrm{a}}$ & & $(0.013)$ & & \\
\hline Interaction with & & & & 0.026 \\
\hline Last two digits $=13^{\mathrm{b}}$ & & & & $(0.021)$ \\
\hline Last digit $=4$ & $\begin{array}{l}-0.031 * * * \\
(0.004)\end{array}$ & $\begin{array}{c}0.002 \\
(0.003)\end{array}$ & $\begin{array}{l}-0.031 * * * \\
(0.004)\end{array}$ & $\begin{array}{c}0.002 \\
(0.003)\end{array}$ \\
\hline Last digit $=8$ & $\begin{array}{l}0.026^{* * *} \\
(0.003)\end{array}$ & $\begin{array}{l}-0.002 \\
(0.003)\end{array}$ & $\begin{array}{l}0.033^{* * *} \\
(0.003)\end{array}$ & $\begin{array}{l}-0.001 \\
(0.003)\end{array}$ \\
\hline Last two digits $=88$ & $\begin{array}{l}0.061 * * * \\
(0.009)\end{array}$ & $\begin{array}{c}0.006 \\
(0.008)\end{array}$ & & \\
\hline Last two digits $=13$ & & & $\begin{array}{l}-0.028 * * \\
(0.013)\end{array}$ & $\begin{array}{l}-0.001 \\
(0.010)\end{array}$ \\
\hline $\begin{array}{l}\text { Census Tract } \\
\text { Dummies }\end{array}$ & No & Yes & No & Yes \\
\hline Street Fixed Effects & No & Yes & No & Yes \\
\hline Adj. R-squared & 0.444 & 0.756 & 0.443 & 0.756 \\
\hline
\end{tabular}

Note: The dependent variable is the natural logarithm of house transaction price. Standard errors are in parentheses. Asterisks indicate the level of statistical significance: $* * * p<0.01, * * p<0.05, * p<0.10$. All regressions include year-month dummies an

a There 1670 houses ending with "88" .

${ }^{\mathrm{b}}$ There 658 houses ending with "13". 